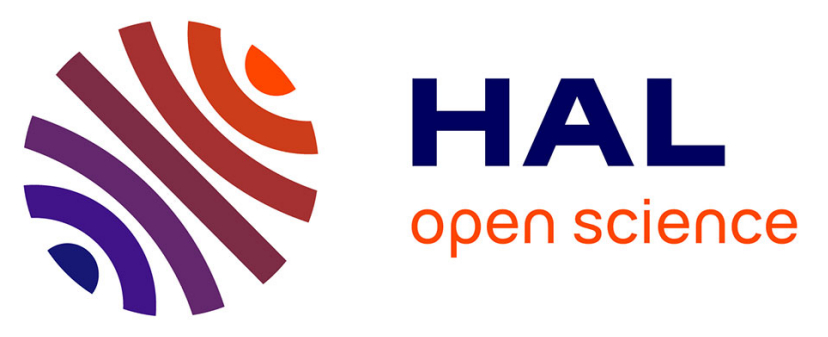

\title{
Study of a dual-mode array integrated in a multi-element transducer for imaging and therapy of prostate cancer
}

Jean-Martial Mari, Guillaume Bouchoux, Jean-Louis Dillenseger, Sophie Gimonet, Alain Birer, Carole Garnier, Lucie Brasset, Ke Wu, Jean-Luc Guey, Gérard Fleury, et al.

\section{To cite this version:}

Jean-Martial Mari, Guillaume Bouchoux, Jean-Louis Dillenseger, Sophie Gimonet, Alain Birer, et al. Study of a dual-mode array integrated in a multi-element transducer for imaging and therapy of prostate cancer. Innovation and Research in BioMedical engineering, 2013, 34 (2), pp.147-158. 10.1016/j.irbm.2013.01.007 . inserm-00825309

\section{HAL Id: inserm-00825309 https://www.hal.inserm.fr/inserm-00825309}

Submitted on 23 May 2013

HAL is a multi-disciplinary open access archive for the deposit and dissemination of scientific research documents, whether they are published or not. The documents may come from teaching and research institutions in France or abroad, or from public or private research centers.
L'archive ouverte pluridisciplinaire HAL, est destinée au dépôt et à la diffusion de documents scientifiques de niveau recherche, publiés ou non, émanant des établissements d'enseignement et de recherche français ou étrangers, des laboratoires publics ou privés. 


\title{
Study of a dual-mode array integrated in a multi-element transducer for imaging and therapy of prostate cancer
}

\author{
Jean-Martial Mari ${ }^{a}$, Guillaume Bouchoux ${ }^{a}$, Jean-Louis Dillenseger ${ }^{c}$, Sophie \\ Gimonet $^{b}$, Alain Birer ${ }^{\mathrm{a}}$, Carole Garnier ${ }^{\mathrm{c}}$, Lucie Brasset ${ }^{\mathrm{a}}$, Ke Wu ${ }^{\mathrm{c}}$, Jean-Luc Guey ${ }^{\mathrm{b}}$, \\ Gérard Fleury ${ }^{\mathrm{b}}$, Jean-Yves Chapelon ${ }^{\mathrm{a}}$, Emmanuel Blanc ${ }^{\mathrm{d}}$ \\ a Inserm, U1032, LabTau, Lyon, F-69003, France ; Université de Lyon, Lyon, F-69003, \\ France

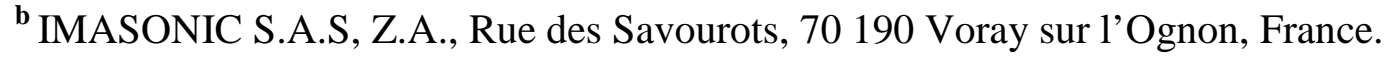 \\ ${ }^{\mathbf{c}}$ Inserm, U1099, Rennes, F-35000, France ; Université de Rennes 1, Laboratoire Traitement \\ du Signal et Image, Rennes, F-35000, France. \\ d EDAP TMS France, 4, rue du Dauphiné - 69120 Vaulx-en-Velin, France
}

\section{Corresponding author :}

Emmanuel Blanc

EDAP TMS France, 4, rue du Dauphiné - 69120 Vaulx-en-Velin, France

Tel: +33(0)4.72.15.31.98 - Fax: +33(0)4.72.15.31.51

\section{Keywords:}

Ultrasound; HIFU; dual mode; multi-element; focal therapy; prostate; cancer.

\begin{abstract}
:
The development of endocavitary dual-mode probes is essential for the accurate treatment of many deep seated cancers which require a high imaging resolution and the capacity to selectively treat focal areas in the region of interest. The MULTIP project is aimed at using state-of-art piezoelectric technologies to design dual-mode ultrasonic probes for cancer-foci treatment and monitoring. In order to allow an efficient surgery planning, the technical study has been accompanied by a volume processing study permitting the design of the ultrasonic imaging/therapy process based on high-resolution-high-quality MRI images. Several prototypes were designed based on a simulation study and implemented: 1) two successive wide-band dual-mode transducer allowing imaging at high resolution $(6 \mathrm{MHz})$ on a wide field of view, and therapy at $3 \mathrm{MHz}$ with a good transduction efficiency $(48 \%$ and $70 \%)$; 2) a therapy-only transducer matrix adapted to the desired curvature with a high transduction efficiency (70\%). Finally, a registration study of MRI volumes on ultrasound volumes has shown that, because of the texture of the ultrasound images, it is more efficient to search at registering the surfaces of the volumes once they have been segmented in each modality, rather than trying to register the two data volumes directly.
\end{abstract}




\section{Introduction}

Therapeutic ultrasound enables the irreversible destruction of deep biological tissue by a focused ultrasonic beam through the natural barriers such as the skin or mucous membranes without damaging them [1-4]. This technique allows minimally invasive therapies beneficial for both patients and health systems. Applications relating to the treatment of prostate cancer, uterine fibroids and atrial fibrillation have already received CE marking and / or approval by the FDA and are used in clinical routine [5-9]. Clinical applications accessible to therapeutic ultrasound can be split into groups characterized either in terms of connection to the patient's body (extracorporeal or intracavitary), or in terms of imaging guidance (ultrasound, MRI or $\mathrm{X}$-ray) or by the users of these technologies (surgeons in the operating room, interventional radiologists and radiotherapists).

Extracorporeal devices implement large ultrasonic transducers to which it is relatively easy to add ultrasound imaging probes without disturbing the therapy ultrasonic fields. However, these devices are limited by the accessibility and the mobility of deeper organs. For example, only about $30 \%$ of the liver's volume can be accessed extracorporeally, $70 \%$ remaining partially obscured by the rib cage. Moreover the liver and the kidney are organs which move under the effect of breathing.

Endocavitary devices offer then interesting alternatives. They cover most applications: urological, gynecological, colorectal or gastroenterological, for which natural channels are well suited. Surgeons and interventional radiologists are also seeking such devices, easier to handle in the operating room or in an MRI enclosure. Endocavitary devices can be brought closer to the targeted organs, which allow to reduce the acoustic powers used and to employ higher frequencies for a better resolution, which in turns permits a better control of the movements of the organs and thus improves the accuracy of the treatment. The aim of the MULTIP project is to improve these devices (MULTIP being the acronym of "Matrice de transducteurs Ultrasonores pour La Thérapie et l'Imagerie de la Prostate") by allowing them to meet the requirements of clinical applications:

- Being small in size to be inserted into the narrower natural routes

- Embed guiding means such as an ultrasound imaging transducer,

- Enable precise treatment of small tumors detected at an early stage,

- Being used in the operating room by a surgeon.

The use of a minimally invasive therapy is usually related to the definition of a precise preoperative planning and an image driven guidance during the intervention. In this study, we focus on endorectal probes for the focal treatment of prostate cancer tumors. In this context, only a precise imaging solution will allow exploiting the treatment precision of our device. For the preoperative planning, only MRI can be used to visualize the prostate and even more discriminate the tumor with sufficient contrast and resolution. In a second step, the fusion or registration of this preoperative information on the per-operative ultrasound images is a prior to access to the necessary therapy precision.

In this paper, we present a synthesis of the results of the studies conducted aiming at developing endocavitary probes designed for prostate cancer (PCa) treatment, which overcome the difficulties raised earlier: the treatment of a volume by $3 \mathrm{D}$ deflection of the ultrasound beam, allowing combination of therapy and imaging in the same probe, and as such further miniaturization of the devices; Image segmentation of the prostate to facilitate 
treatment planning by allowing the fusion of the ultrasound images on acquired MRI volumes. Firstly, the methods for designing and testing the prototype transducers are presented before describing a new method for segmenting images of the prostate

\section{The MULTIP project: application of endocavitary devices to PCa treatment.}

In France in year 2006, the increase in prostate cancer occurrence has been estimated to be $100 \%$ compared to year 2000, raising the total number of men involved to 76518 [10]. Current radical whole-gland surgery or radiotherapy often induce side-effects such as urinary incontinence, erectile dysfunction, and bowel toxicity [11]. Focal treatment of the cancer nodes instead of whole gland surgery is the best chance of maintaining satisfactory life style and reducing the impact of prostate cancer surgery on the society. High Intensity Focused Ultrasound (HIFU) technology is particularly well suited for focal treatment of prostate cancer since the procedure is non-invasive, effective thus offering an excellent benefice to risk ratio $[8,9,12]$. As of today two companies (EDAP-TMS and US HIFU) obtained market approval for localized prostate cancer treatment with HIFU. They both use ultrasound imaging technology to guide the treatment. Two companies (INSIGHTEC and PROFOUND MEDICAL) are starting clinical trials for the same application with MRI guidance. Table 1 summarizes the achievements of the companies involved in the development of focused ultrasound therapy devices.

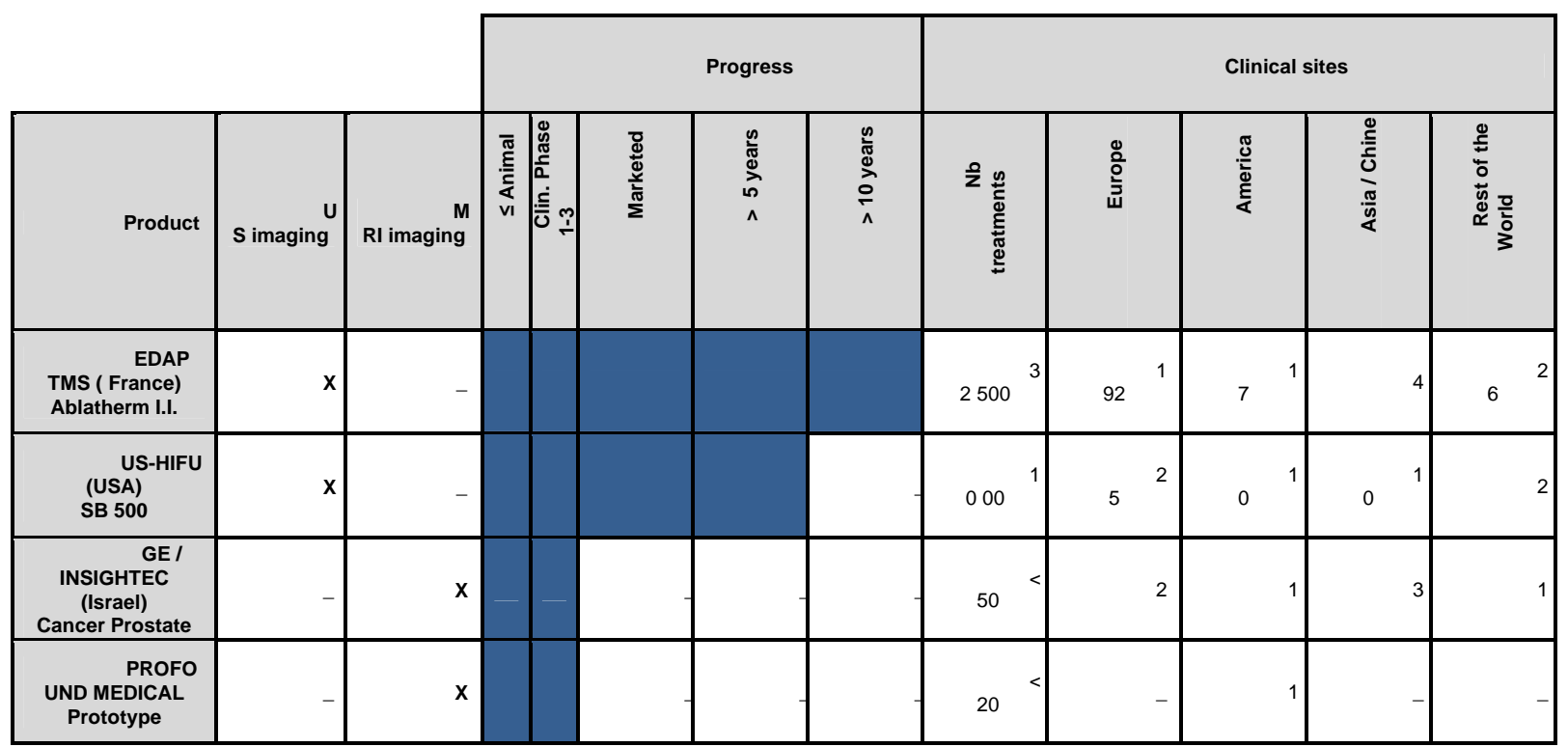

Table 1 : Summary of the companies involved in the development of focused ultrasound devices for PCa treatment

An "Integrated Imaging" version of the Ablatherm ${ }^{\circledR}$ was put on the market in 2005. The geometry of the transducer has been modified to receive at its center an imaging cell. This geometric modification of the transducer had an impact on the geometry of the ultrasound beam and therefore the clinical performance. It was then necessary to extend the pre-clinical studies and clinical trials to find new processing parameters which allowed maintaining or improving the clinical performance of the new product. If the resulting performances are now 
well established and recognized by many national authorities, there are still some limitations in particular in the use of transducers with a fixed focal length. It is limited to $45 \mathrm{~mm}$, and the complete treatment of large prostates cannot be achieved in a single session. In $10 \%$ to $20 \%$ of cases it is necessary to use a second procedure. The fixed focus aspect also leads to overtreat the central area of the prostate compared to the peripheral regions.

The current trend is to perform focal therapy by only treating the diseased area within an organ $[8,9,11,12]$. Large treatment volume and time consuming procedure will not be required anymore. Multi elements transducer allowing electronic deflection of the ultrasound beam [13] combined with dual-mode imaging array will ensure complete and fast treatment procedure without necessity of complex device technologies integration making these devices compatible with both ultrasound and / or MRI guidance.

\section{Simulations and prototyping}

The general concept of dual-mode probe is presented on Figure 1. The purpose of the central dual-mode part of the probe is to allow both imaging and therapy from the same transducer surface. Therefore, no therapeutic ultrasound emission surface is lost due to the inclusion of an imaging-only transducer, which can be critical due to miniaturization constraints. A high frequency operation of the dual-mode array is required for achieving a good resolution, comparable to the current imaging systems (e.g. $6 \mathrm{MHz}$ with the Ablatherm $^{\circledR}$ ). On the other hand, the dual-mode array should be operated at lower frequencies for therapy, as performed in the current systems (e.g. $3 \mathrm{MHz}$ with the Ablatherm). Indeed treating at high frequencies would decrease the penetration and increase the risk of heating the intervening healthy tissues away from the focus.

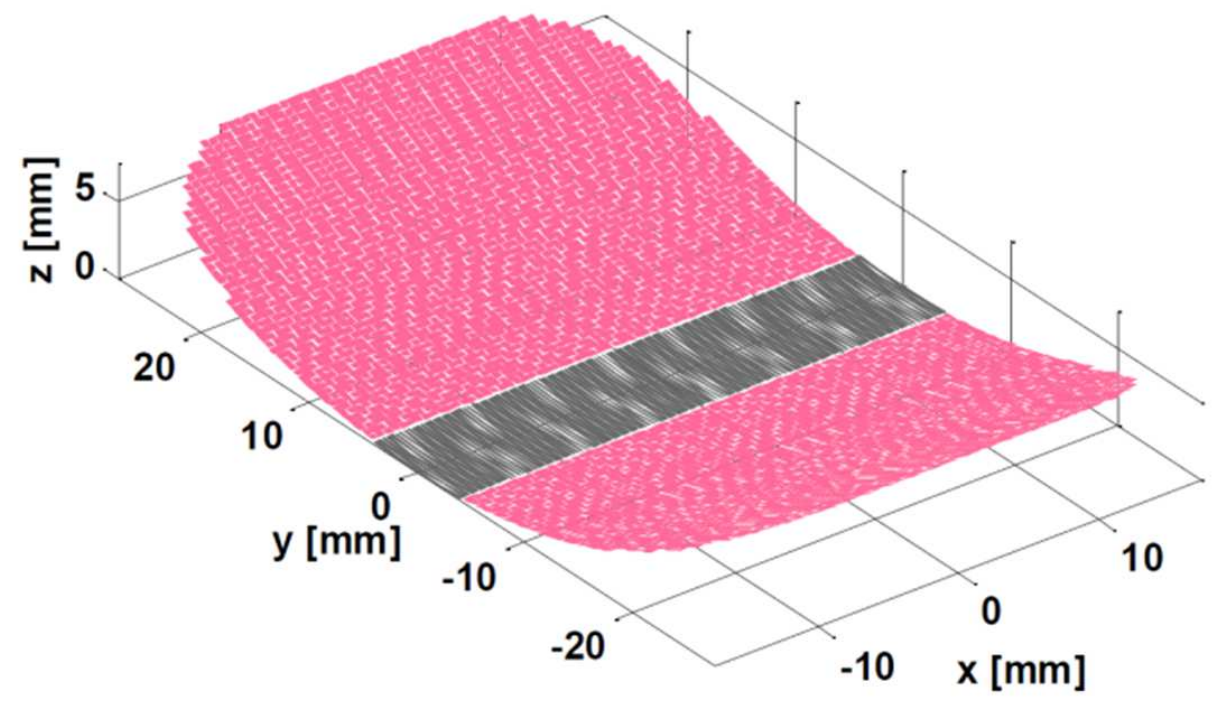

Figure 1: Design of the probe, with a dual-mode center part (gray) surrounded with elements dedicated to therapy-only.

As such, the probe aimed at being developed is a dual-mode dual-frequency transducer. The imaging part should be capable of forming high resolution images on a field of view as 
wide as possible allowing the visualization of the entire prostate, which implies an ability to steer the beam. In the context of this project, typical power transmit efficiency of a therapy transducer is about $60-70 \%$, depending of electrical environmental conditions and electrical impedance matching circuits included in the electrical environment [14,15]. Given the dualmode nature of a section of the probe to be developed, the project aimed at developing a transducer with an efficiency as close as possible to these numbers.

Simulations have been conducted using the Field II software [16] in order to determine the optimum probe parameters for both imaging and therapy modes: size of the elements, kerf width [17], and geometry.

\subsection{Numerical design of the imaging and therapy parts}

\subsubsection{Imaging}

Simulation tools and models of transducers were implemented to assess the images obtained with different network configurations comparing them with those obtained with the current curved array Ablatherm ${ }^{\circledR}$ system. Simulations were conducted for two geometries: spherical and cylindrical. The scatterers map [18] used to simulate prostate exams in conjunction with the FieldII software [16] is provided on Figure 2. To synthesize the results obtained in MULTIP, it was found that the lateral resolution of cross-sectional images is always better with concave or cylindrical arrays, since they benefits from a much wider aperture (see Table 2). This is the case even if the frequency is decreased (for example $3 \mathrm{MHz}$ while the frequency currently used is of the order of $7 \mathrm{MHz}$ ). The axial resolution obtained with the Ablatherm ${ }^{\circledR}$ configuration is comparable to the images formed with the dual-mode array configurations at $6 \mathrm{MHz}$, but twice as good than images formed at $3 \mathrm{MHz}$. In almost all configurations tested, in the absence of side lobes noise, we came to identify important structures on the images of phantom prostate. The appearance of speckle is isotropic, and interfaces are often more visible with the tested configurations than with the reference one. As the axial resolution is coarser (especially at $3 \mathrm{MHz}$ ), the rectal wall (parallel to the transducer) may be more difficult to discern. In general, we can conclude that in terms of resolution, the images formed at $6 \mathrm{MHz}$ with dual-mode large strips are better than those obtained with the current configuration. For the images formed at $3 \mathrm{MHz}$, as the lateral resolution is better but the axial resolution much worse. A potential issue lies in the presence of grating lobes generated by the beam steering. In fact, prostate gland is greater than the imaging probe strip, and for obtaining an image covering the whole of the gland, the beam must be steered to enlarge the field of view. If the pitch is too large, grating lobes appear, and the noise they bring is in most cases unacceptable (Figure 3): in the prostate-phantom images, the noise greatly reduces the contrast, blurs the contours of the body and prevents discerning the structures. In conclusion, the pitch must be chosen to avoid the appearance of grating lobes. However, a too small pitch may set technological problems: in particular, a too large number of elements can become difficult to electrically wire and control. Conversely, the imaging frequency can be decreased; for example from $6 \mathrm{MHz}$ to $3 \mathrm{MHz}$, and the pitch increased from $150 \mu \mathrm{m}$ to $300 \mu \mathrm{m}$. However, as discussed above, the resolution decreases with frequency. Another way to increase the pitch without raising the noise caused by the grating lobes is to limit the beam deflection angle. For this purpose, a moving sub-aperture technique can be 
used. In this case a cylindrical geometry (focused in the elevation direction) is preferred to a spherical geometry, for which it would be necessary to compensate electronically the longitudinal curvature. The simulations showed that using this technique, the pitch can be increased (at least until $0.78 \lambda$ ) without occurrence of noise (Table 2), especially if it is acceptable to limit the lateral resolution of the image on the edges. The cylindrical configuration results shown on Figure 4 take advantage of all the aspects of the dualfrequency dual-mode array. In this case we agree to degrade the resolution on the sides by reducing the transmit sub-aperture and the imaging frequency, but the resolution in the center of the image (where it is the most important) is optimal and no noise from the lobes network is observed. With this type of operation a pitch at $1.2 \lambda$ for imaging at $6 \mathrm{MHz}$ is acceptable. The geometry in elevation of the transducer array was also studied. The focal length in this direction was set to $60 \mathrm{~mm}$ (the focal length of the Ablatherm® therapy transducer). It has been shown that an elevation aperture of 5 to $8 \mathrm{~mm}$ gives a beam size in the elevation dimension comparable to that obtained with the current imaging array. 3D images of a phantom prostate obtained by translation of a transducer in transverse configuration showed that with an elevation aperture of $8 \mathrm{~mm}$ and a frequency of $6 \mathrm{MHz}$ image quality comparable to that obtained with Ablatherm®.

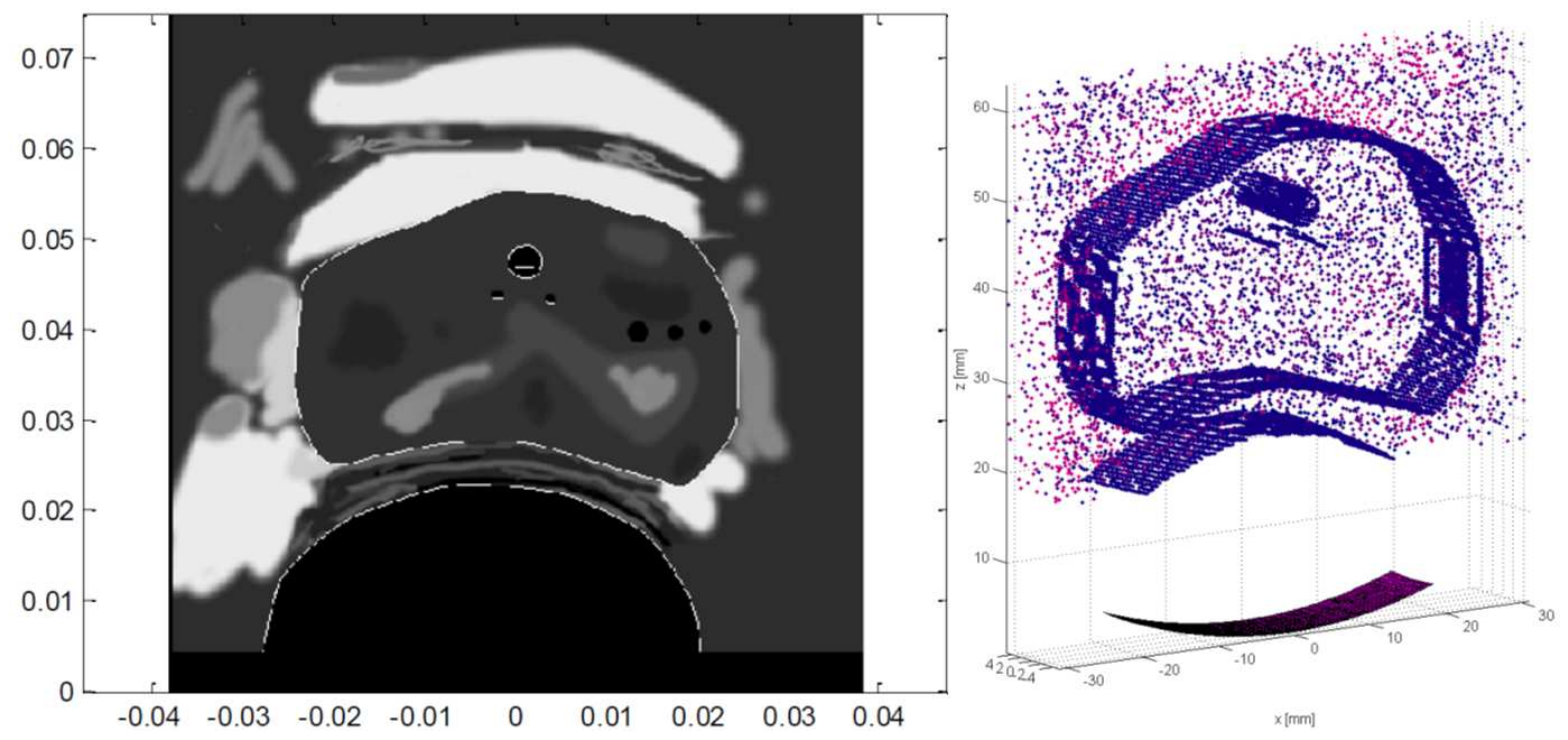

Figure 2: Left, an echogeneicity map derived from a segmentation of a B-mode image acquired on a prostate with the current ultrasound probe of the Ablatherm ${ }^{\circledR}$. One distinguishes in particular the contours of the prostate, the rectal wall, urethra. The interfaces are drawn in white with a one-pixel line thickness. Right: Prostate phantom consisting of point scatterers (only a portion is shown for clarity of the image). 

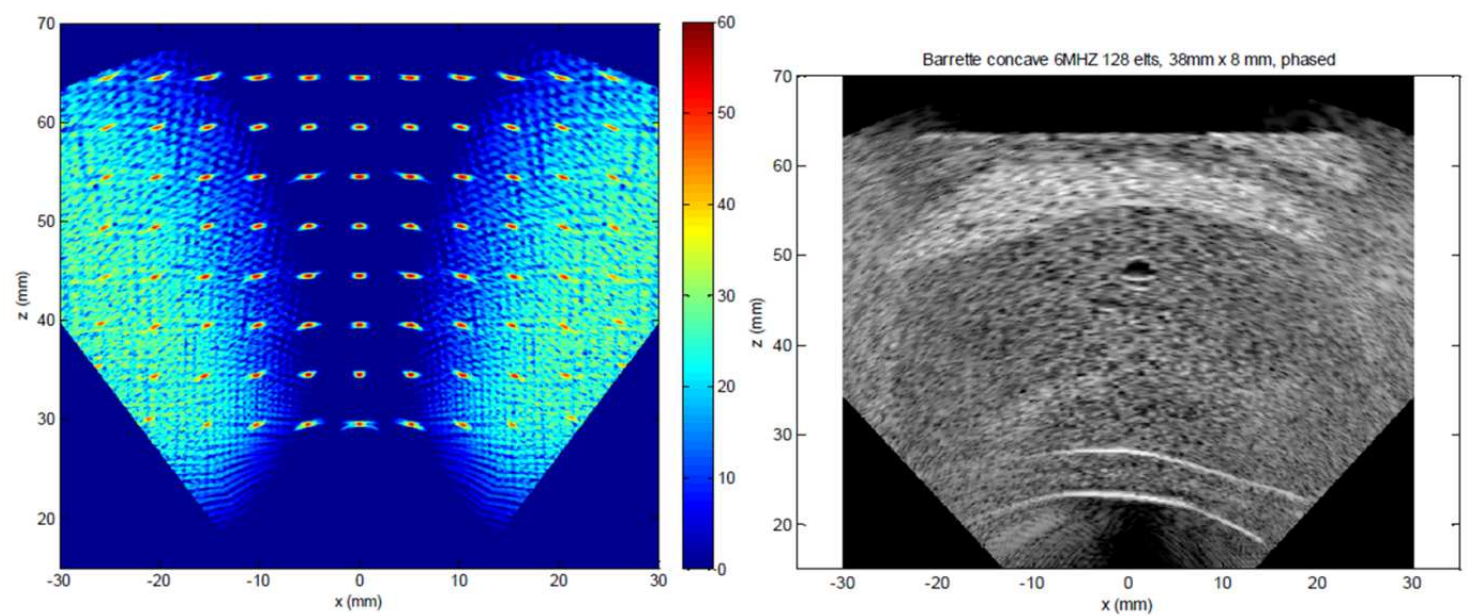

Figure 3: Simulated images (left: resolution array, right: B-mode image) for a concave probe $(\mathrm{F}=60 \mathrm{~mm}), 38 \mathrm{~mm}$ in length, comprising 128 elements and operating at $6 \mathrm{MHz}$

\begin{tabular}{|c|c|c|c|c|c|c|c|}
\hline Configuration & $\begin{array}{c}128 \\
\text { elements }\end{array}$ & $\begin{array}{c}192 \\
\text { elements }\end{array}$ & $\begin{array}{c}256 \\
\text { elements }\end{array}$ & $\begin{array}{c}128 \\
\text { elements, } \\
3 \mathrm{MHz}\end{array}$ & $\begin{array}{l}\text { Cylindrical } \\
192 \text { elements }\end{array}$ & $\begin{array}{l}\text { Cylindrical } 96 \\
\text { elements } 3 \mathrm{MHz}\end{array}$ & $\begin{array}{c}\text { Cylindrical } \\
128 \text { elements } \\
3-6 \mathrm{MHz}\end{array}$ \\
\hline Centre frequency (MHz) & 6 & 6 & 6 & 3 & 6 & 3 & $3-6$ \\
\hline Nb elements & 128 & 192 & 256 & 128 & 1292 & 96 & 128 \\
\hline Pitch $(\mu \mathrm{m}, \lambda)$ & $302 ; 1.18$ & $201 ; 0.78$ & $150 ; 0.59$ & $302 ; 0.59$ & $200 ; 0.78$ & $400 ; 0.78$ & $302 ; 0.59-1.18$ \\
\hline $\mathrm{Nb}$ of active elements & 100 & 100 & 100 & 100 & $\begin{array}{l}\text { Variable } \\
\text { num }=2)\end{array}(\mathrm{F}-$ & $\begin{array}{c}\text { Variable } \\
(\mathrm{F}-\text {-num }=2)\end{array}$ & $\begin{array}{l}\text { Variable } \\
\text { num }=2)\end{array}\left(\begin{array}{l}(\mathrm{F}- \\
\end{array}\right.$ \\
\hline $\begin{array}{l}-6 \mathrm{~dB} \text { lateral resolution } \\
\text { (current } 850-1800 \mu \mathrm{m})\end{array}$ & $350-700$ & $400-750$ & $500-1000$ & $750-1350$ & $\begin{array}{l}800-900 \\
\text { (center) }\end{array}$ & $\begin{array}{c}1650-2000 \\
\text { (center) }\end{array}$ & $\begin{array}{c}800-1000 \\
\text { (center) }\end{array}$ \\
\hline $\begin{array}{l}-6 \text { dB axial resolution } \\
\text { (current } 200 \mu \mathrm{m})\end{array}$ & 300 & 300 & 300 & 550 & 300 & 600 & 300 (center) \\
\hline $\begin{array}{c}\text { Noise level (current -54 } \\
\mathrm{dB} \text { ) }\end{array}$ & -25 & -32 & -50 & -50 & -46 & -42 & -44 \\
\hline $\begin{array}{l}\text { Image width with noise < } \\
-40 \mathrm{~dB} \text {, in } \mathrm{mm} \text {; current } 60 \\
\mathrm{~mm} \text { ) }\end{array}$ & 20 & 40 & 60 & 60 & 60 & 60 & 60 \\
\hline
\end{tabular}

Table 2 : Configurations tested (focal radius $60 \mathrm{~mm}$, probe length $38 \mathrm{~mm}$ ) and results in terms of resolution and noise level ( $\mathrm{Nb}$ : number; F-num: F-number).
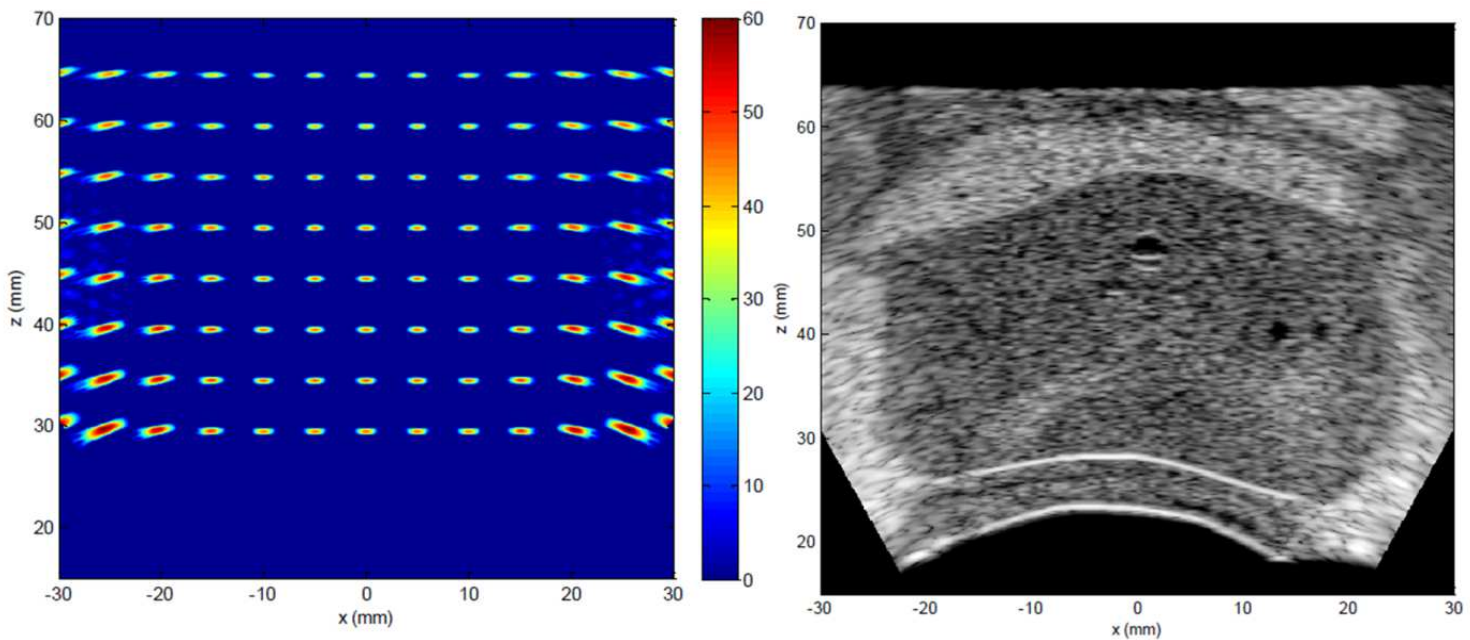

Figure 4: Simulated images (left: resolution array, right: B-mode image) for a transverse, cylindrical probe with $38 \mathrm{~mm}$ length, 128 elements and operating at $3 \mathrm{MHz}$ (for the lines with the larger deflection) to $6 \mathrm{MHz}$ (for the lines oriented along the $\mathrm{z}$ axis). The focal number is 2 , except at the edges of the image where it is higher 


\subsubsection{Therapy}

In this section, the therapy-only part of the MULTIP probe is addressed. A dual-mode imaging array placed at the center of the therapy probe is assumed, and the rest of the available surface is used only for power transmission (Figure 1). The design parameters of the therapy part were empirically determined by taking into consideration both technological and functional constraints (Table 3). A full 2D grid for a 3D beam steering would lead to a prohibitively large number of elements. By limiting the maximum deflection angles and tolerating grating lobes to some extent, the array pitch can be increased and the total number of elements limited. The independent elements count can be further reduced by connecting electrically symmetrical elements in a $1.5 \mathrm{D}$ or $1.25 \mathrm{D}$ arrays configuration $[15,17]$. This approach was investigated in order to achieve a technologically feasible design. The curvature of the therapy surface, the type and method of focusing, and the elements grid have to be determined. Simulations were performed assuming that the propagation is linear, in a homogeneous medium, and the transducer is excited in harmonic regime, and no cavitation occurs. The transducer considered here is cylindrical. The ultrasonic fields obtained with the tested configurations were calculated using Field II. To estimate the tissue heating induced by the ultrasound exposures, a thermal model was developed.

\begin{tabular}{|l|l|}
\hline Actives dimensions & Maximum of $57.5 \mathrm{~mm}$ (y axis) $\times 35 \mathrm{~mm}(x$ axis $)$ \\
\hline Curvature & Cylindrical $(55 \mathrm{~mm})$ \\
\hline Imaging array & Inclusion of a $35 \mathrm{~mm} \times 8 \mathrm{~mm}$ dual-mode array of 117 elements. \\
\hline Frequency & $3 \mathrm{MHz}$, continuous. \\
\hline Number of elements & $\begin{array}{l}\text { Maximum of } 400 \text { elements (without the imaging array) for a maximum of } 200 \\
\text { electrical channels. }\end{array}$ \\
\hline Therapy method & To be determined. \\
\hline Elements geometry (grid) & Elements of identical surface, with a shape to determine. \\
\hline Treatment area & $\mathrm{A} x z$ rectangle :-10mm $<x<10 \mathrm{~mm} ; 20 \mathrm{~mm}<\mathrm{z}<60 \mathrm{~mm}$ \\
\hline
\end{tabular}

Table 3 : Configurations tested (focal radius $60 \mathrm{~mm}$, probe length $38 \mathrm{~mm}$ ) and results in terms of resolution and noise level (Nb: number; F-num: F-number).

From the simulated ultrasonic field, knowing the attenuation in the tissues [14,19], the deposited heat power per unit volume is computed and used as a heat source term in the modified heat equation (bioheat transfer equation, or BHTE) [20]. This equation is solved numerically with the method proposed by [21]. The acoustic and thermal parameters used in the simulations are summarized in Table 4.

\begin{tabular}{|l|l|}
\hline Speed of sound & $1540 \mathrm{~m} / \mathrm{s}$ \\
\hline Attenuation & $0.5 \mathrm{~dB} / \mathrm{cm} / \mathrm{MHz}$ \\
\hline Density & $1050 \mathrm{~kg} / \mathrm{m}^{3}$ \\
\hline Heat capacity of the tissues & $3639 \mathrm{~J} / \mathrm{kg} /{ }^{\circ} \mathrm{C}$ \\
\hline Heat conductivity of the tissues & $0.56 \mathrm{~W} / \mathrm{m} /{ }^{\circ} \mathrm{C}$ \\
\hline Perfusion & $30 \mathrm{~kg} / \mathrm{m}^{3} / \mathrm{s}$ \\
\hline Heat capacity of the blood & $3825 \mathrm{~J} / \mathrm{kg} /{ }^{\circ} \mathrm{C}$ \\
\hline Blood temperature & $37^{\circ} \mathrm{C}$ \\
\hline
\end{tabular}

Table 4 : Acoustic and thermal parameters used for the simulations 


\subsubsection{Treatment strategy simulations}

Before studying the subdivision of the transducer's surface, a treatment strategy must be chosen. In fact, the pattern of the elements in the array must be determined according to the focusing needs. Several types of treatments were considered: the scanning of the area to be treated with one or two focal points.

A complete therapy sequence consists in juxtaposing several elementary lesions to treat completely the targeted zone. Typically, the probe is positioned so that the targeted zone is centered on its acoustic axis. Therefore, a treatment scheme where the targeted zone is scanned with pairs of elementary lesions that are symmetrical along the $y z$ plane (as defined on Figure 1) can be used. In a classical approach, the two symmetrical lesions can be produced by switching a single ultrasound focal point between them. Considering the relatively long thermal time constants in the soft tissues, an almost equivalent temperature rise map can be obtained with a multi-focal beam focused on both the elementary lesions sites at the same time, by using the proper array excitation scheme. In this case, as the two lesions are symmetrical, the excitation pattern will also be symmetrical. This allows connecting electrically the elements that are symmetrical along the $y z$ plane together, which divides the number of independent channels by two. Similarly, if the focal points are all in the $x z$ plane (as specified in Table 3), a second symmetry plane ( $x z$ ) allows dividing again by two the number of independent elements.

Simulations were performed in order to compare the ultrasound fields and the temperature maps obtained with the classical approach (alternating single focal points), and the proposed approach (multiple symmetrical focusing). Results are displayed on Figure 5, which shows on the right the temperature elevation when the focal point is exposed until a target temperature of $72^{\circ} \mathrm{C}$ is reached, and then refocusing the transducer to a symmetrical focal point (the mirror image of the first relative to $y z$ ) until reaching $72^{\circ} \mathrm{C}$. Figure 6 shows the ultrasound field obtained by focusing simultaneously on two symmetrical focal points in the plane $y z$. The simulated temperature rise for two simultaneous focal points is almost identical to the case of one focal point alternated rapidly.
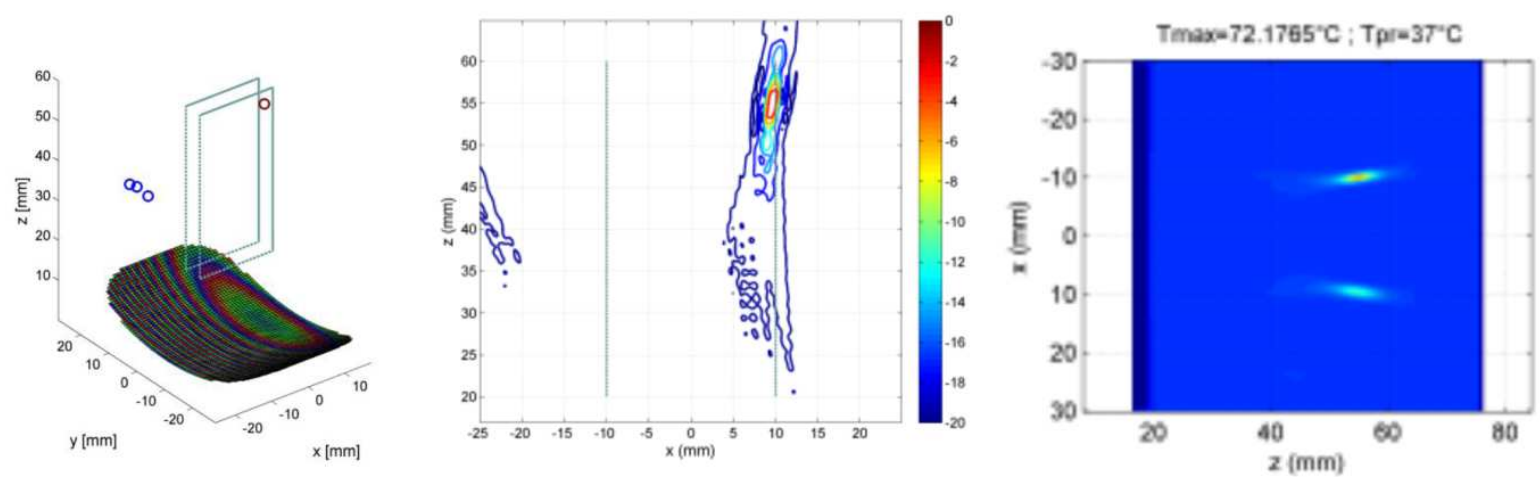

Figure 5: Field obtained with a single focal point located at one end of the targeted area for treatment. On the left, the transducer is represented with the local maxima of the acoustic field obtained by simulation. The color of the elements on the transducer indicates the phase of the excitation. A straight xz cut of the field is shown on the center (color scale in $\mathrm{dB}$ on the right figure). On the right is shown the spatial distribution of the temperature rise simulated for a shot towards the focal point, alternating with a shot to a symmetrical focal point $\left(\right.$ ISPTA $\left.=1000 \mathrm{~W} / \mathrm{cm}^{2}\right)$. 

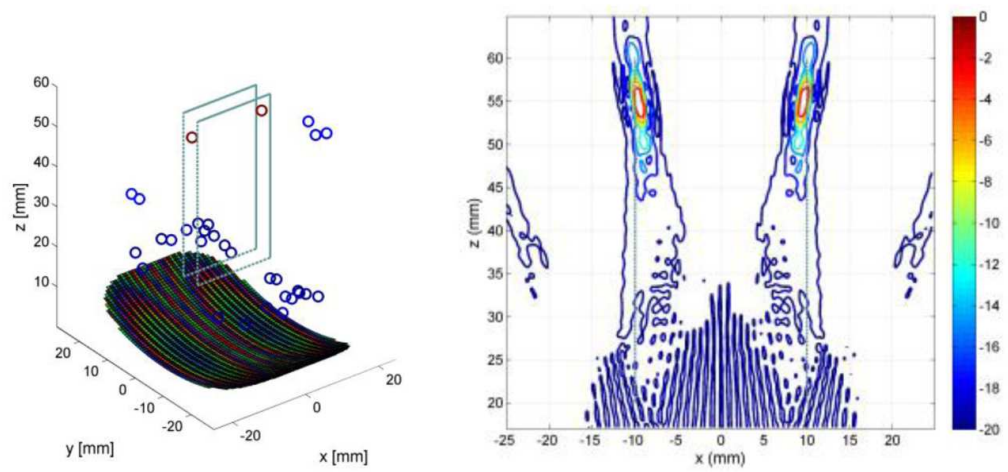

Figure 6: Fields obtained by focusing on two focal points symmetrical along the plane yz. On the left, the transducer is represented with the local maxima of the acoustic field obtained by simulation. The color of the elements on the transducer indicates the phase of the excitation. The color of the local maxima (circles in the figure) indicates the intensity (color scale in $\mathrm{dB}$ on the right figure). A straight cut $x z$ field is shown on the right.

\subsubsection{Study of the therapy transducer's surface subdivision}

The choice was made to simulate the field and optimize the transducer's surface subdivision for two symmetrical focal points, in order to reduce the number of independent elements. The goal is to optimize the acoustical intensity at the targeted area. The acoustic field and the corresponding temperatures have been computed for different types of subdivisions of the surface, illustrated on Figure 7. To perform the optimization (of the subdivision size or elements regrouping) the value of the calculated field for a set of control points in the targeted volume is compared to a reference value (desired acoustic intensity, obtained with an ideal reference). Optimal grid parameters are searched by minimizing a cost function using a genetic algorithm [22]. The cost function is computed using the ratios between the actual intensity obtained at the checkpoints and the expected value (obtained with the ideal reference transducer). Acoustic fields' profiles along the $\mathrm{z}$ axis, and the corresponding temperature rise, were calculated for the optimized configurations found and are compared on Figure 8. The configurations explored were a regular grid with a resolution to be optimized, an irregular grid with varying line and columns sizes, a regular grid of rows of different widths, and a regular grid of $1 \mathrm{~mm}$ side elements grouped to respect the 400 maximum channels fixed by the specifications. Both configurations of irregular grid (groups of elements and irregular grid) give better quality profiles than those obtained for the regular grid configuration (for which the temperature rise on the rectal wall is little higher). 

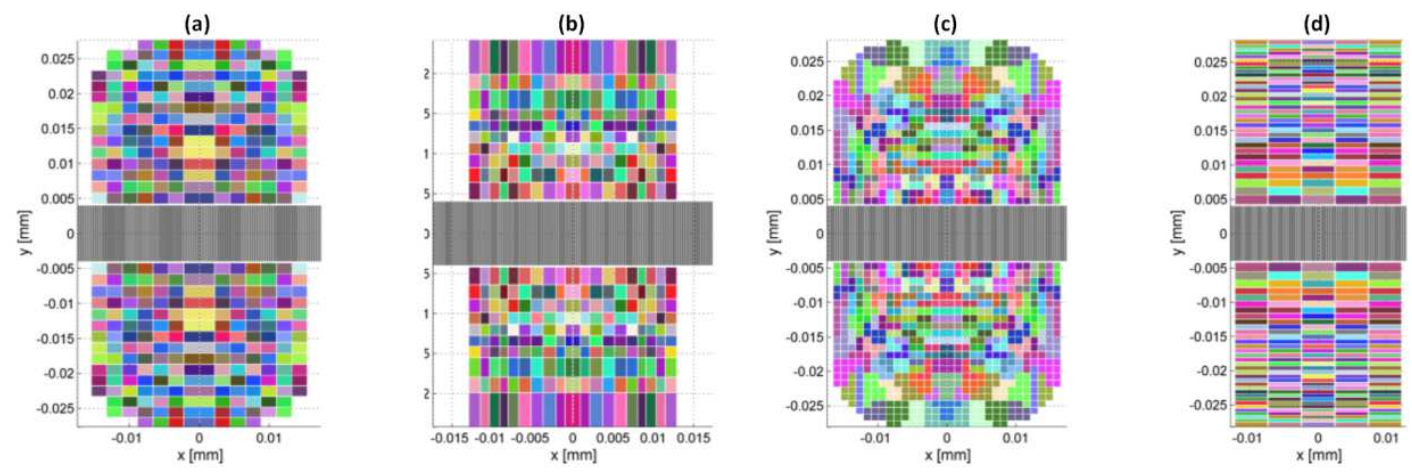

Figure 7: Examples of regular (a, $2 \mathrm{~mm}$ ), irregular (b), grouped elements (c, $1 \mathrm{~mm}$ ) and regular column of varying height (d). Elements electrically connected are displayed in the same color.
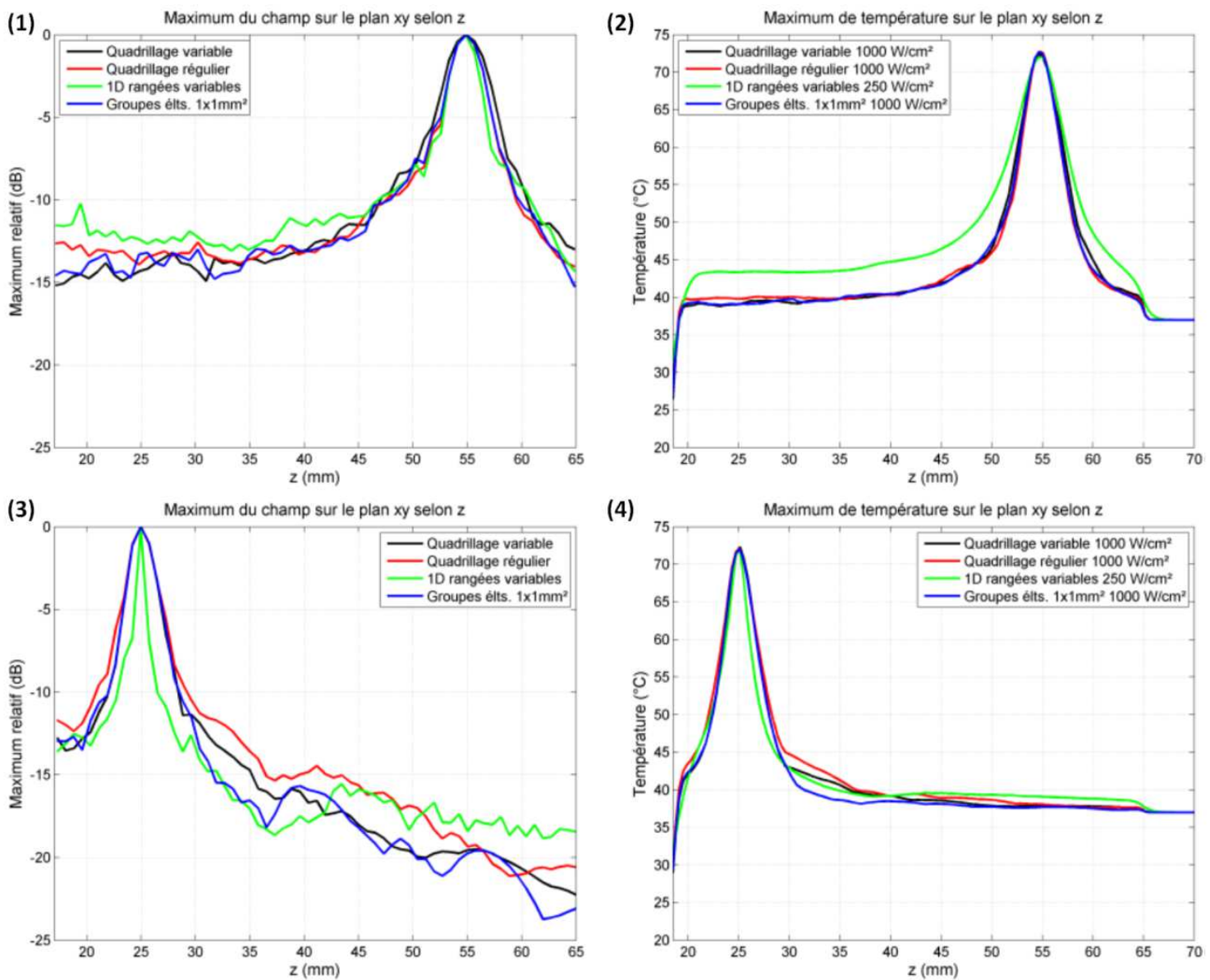

Figure 8: Acoustic intensity profiles (1 and 3) and elevation of temperature after firing with an $\mathrm{I}_{\mathrm{SPTA}}$ of $1000 \mathrm{~W} / \mathrm{cm}^{2}$ interrupted after reaching a temperature of $72{ }^{\circ} \mathrm{C}$ ( 2 and 4 ), for the following configurations: regular grid, variable grid, groups of elements, regular column of varying height elements. Fields and temperatures are calculated for a focal length of $25 \mathrm{~mm}$ ( 1 and 2$)$ and $55 \mathrm{~mm}$ ( 3 and 4$)$.

\subsection{Prototyping}

Based on the study previously performed, prototypes have been designed by the project partner Imasonic (Voray sur l'Ognon, France). Two imaging arrays and one therapy array demonstrators have been fabricated. 


\subsubsection{Dual-mode prototype}

The imaging prototype was designed with the following characteristics derived from the simulation study: imaging at $6 \mathrm{MHz}$, therapy at $3 \mathrm{MHz}, 96$ elements, $300 \mu \mathrm{m}$ pitch, $8 \mathrm{~mm}$ height, waterproof, the first prototype being plane and the second prototype having an elevation geometrical focus at $60 \mathrm{~mm}$ (Figure 9).

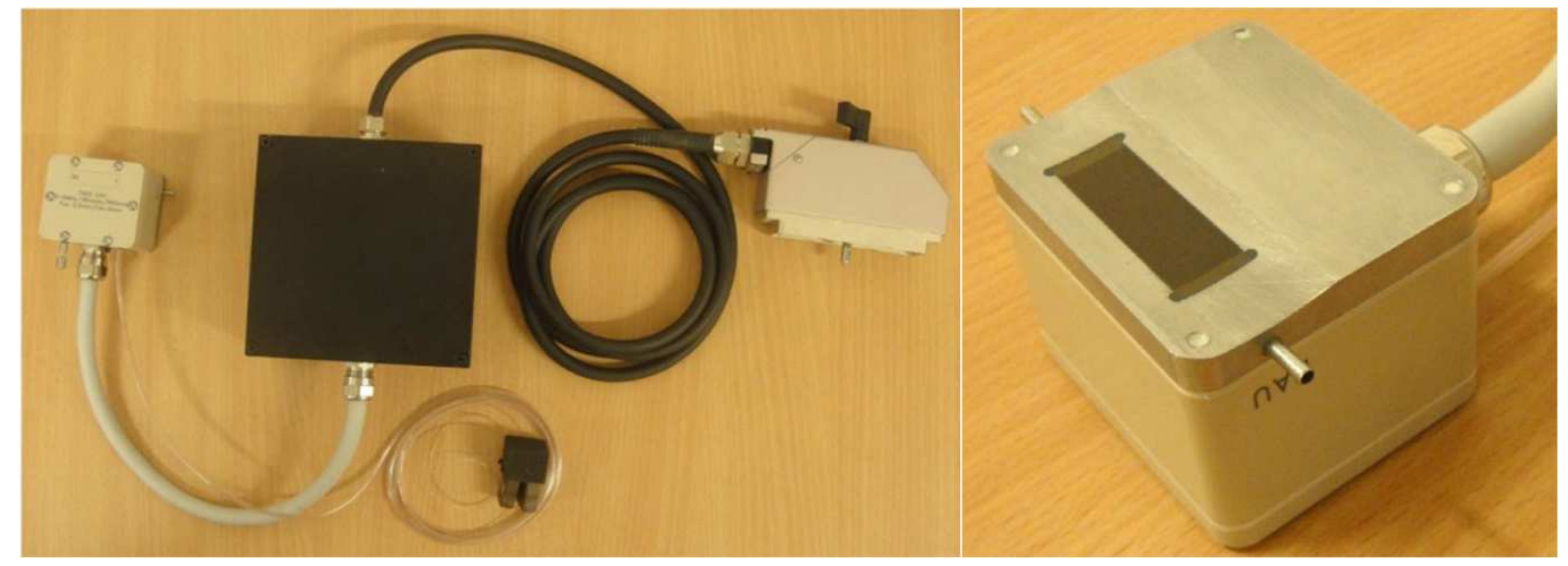

Figure 9: Pictures of the second prototype of the dual-mode probe.

\subsubsection{Dual Mode imaging capabilities}

Imaging capacities were tested for the first prototype on an ATS tissue mimicking phantom (ATS Laboratories, Bridgeport, United States) and an Ultrasonix RP 500 ultrasound scanner (Ultrasonix, Richmond, Canada). The tests were performed by transmitting pulses at a $5 \mathrm{MHz}$ center frequency (maximum frequency allowed by the probe+scanner system). The image obtained is compared to the one obtained by connecting the Ablatherm ${ }^{\circledR}$ imaging probe to the scanner. Images are provided on Figure 10. The imaging tests results show that the image produced by the dual-mode probe is of greater quality than the one obtained on the previous Ablatherm ${ }^{\circledR}$ probe in similar imaging conditions. The Dual-mode probe developed allowed to perform the imaging at a high frequency, which demonstrates the capacity of such probe to ensure high resolution imaging, while being designed to work also at low frequency. For the second prototype (aiming at increasing the transduction efficiency, detailed further in the document), the spectra of the impulse responses for two of the elements of the probe $\left(\mathrm{n}^{\circ} 48\right.$ and 49) are provided on Figure 11. The bandwidth of the resulting probe covers the $3 \mathrm{MHz}-6$ $\mathrm{MHz}$ range as expected. The impulse response is short, and is suitable for imaging purposes. 

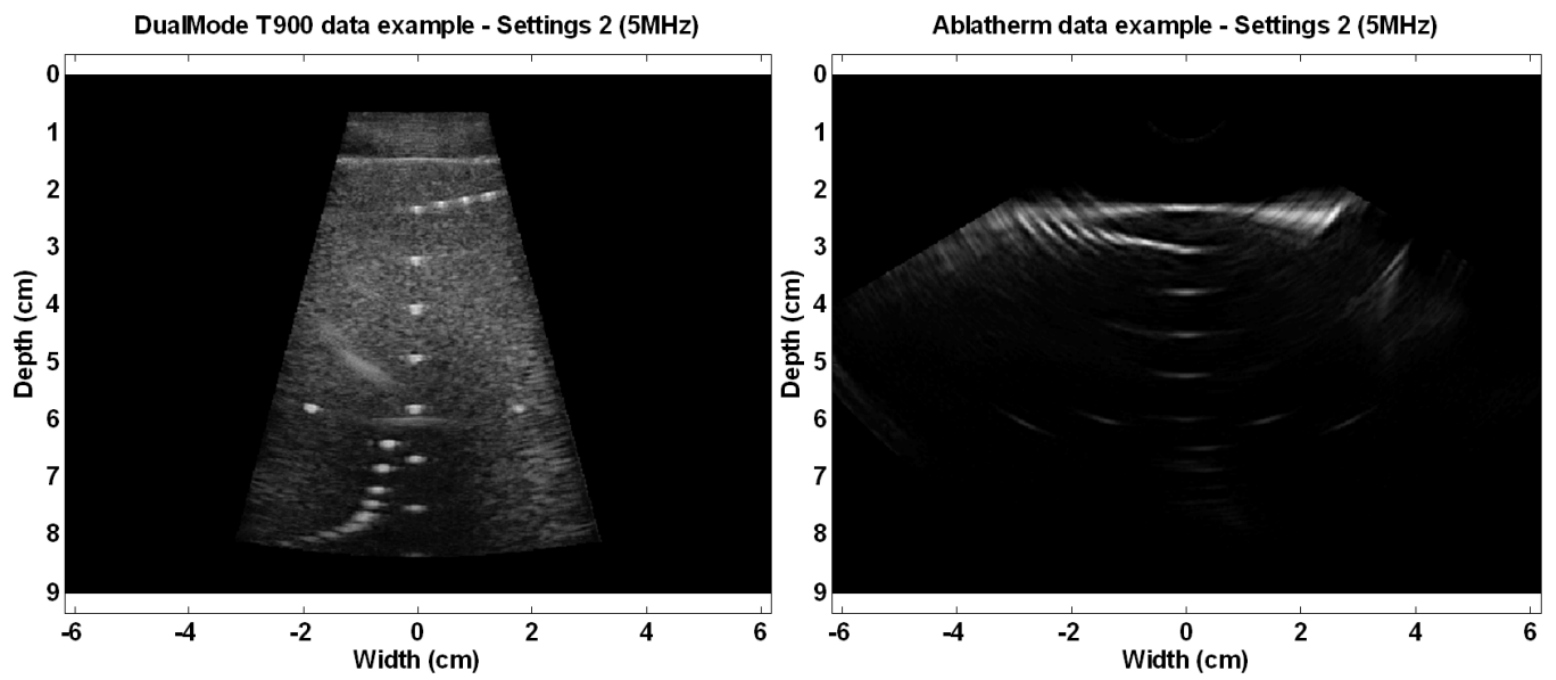

Figure 10: Images of the resolution array of the ATS phantom using the first prototype of Dual-mode probe (left) and the Ablatherm ${ }^{\circledR}$ probe (right).The resulting signal to noise ratio of the dual-mode probe proves superior to the one of the Ablatherm ${ }^{\circledR}$ probe in similar imaging conditions.

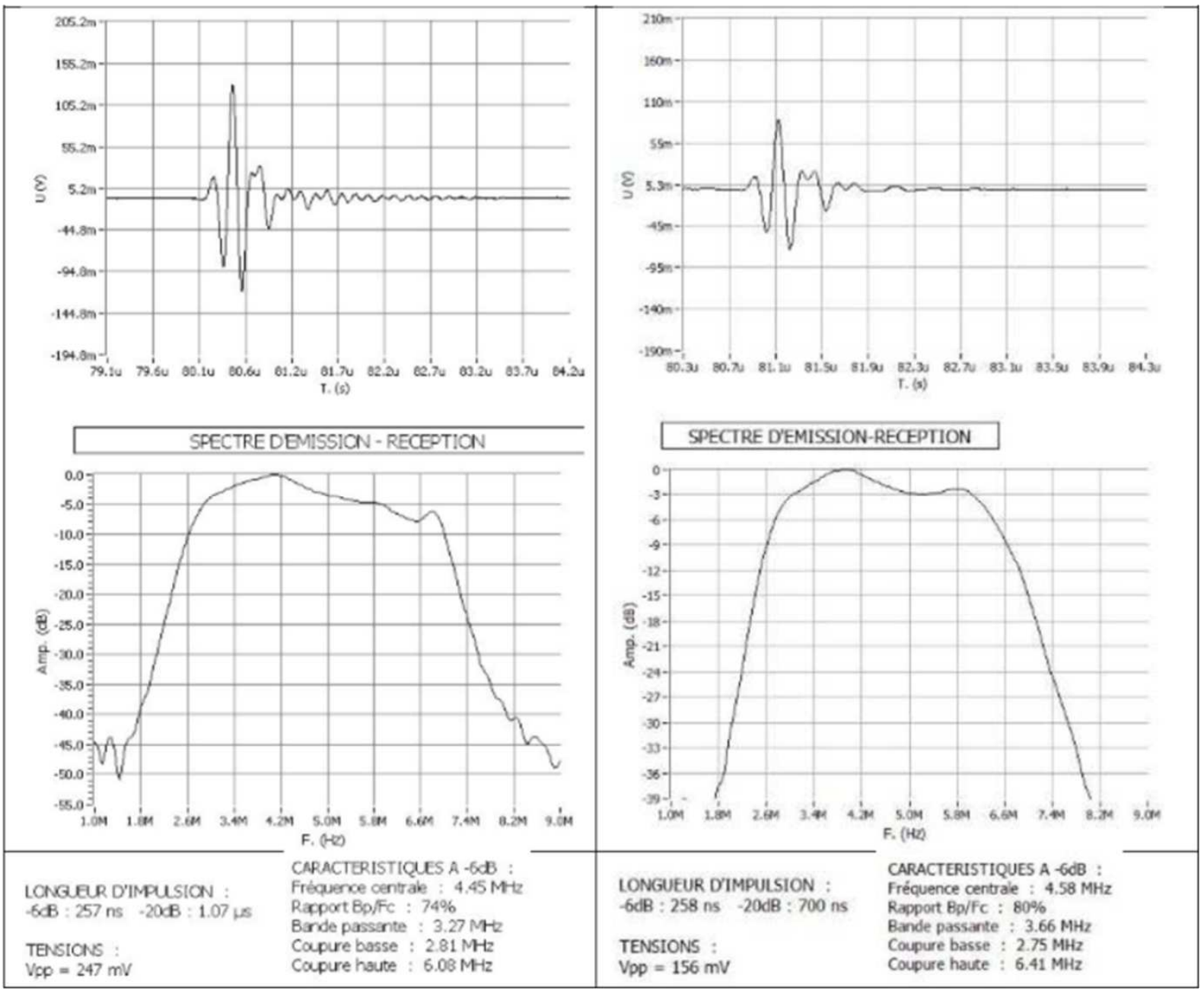

Figure 11: Impulse response and its spectrum measured on element 48 (left) and 49

(right) of the second imaging probe prototype 


\subsubsection{Dual-mode array therapy capabilities}

Regarding the therapy mode of the dual-mode transducer, the mean power transmit efficiency has been measured for both prototypes. The mean value obtained is $48 \% \pm 2 \%$ for prototype 1 , the maximum being reached at $4 \mathrm{MHz}$, which is typically insufficient, but the preliminary characterization results for prototype 2 gave a mean transduction efficiency of $70 \%$ at the targeted $3 \mathrm{MHz}$ centre frequency.

\subsubsection{Therapy prototype}

The therapy prototype was designed with the following characteristics derived from the simulation study: therapy at $3 \mathrm{MHz}, 456$ elements (according to a design similar to Figure 7a), 114 channels with symmetrical wiring, and geometrical focus at $60 \mathrm{~mm}$. The prototype is shown on Figure 12-left.The transducer efficiency has been characterized as a function of the transmit frequency by the radiation force balance method. Results are provided on Figure 12right. The transmit efficiency reaches $70 \%$ at $3 \mathrm{MHz}$, which suitable for a therapy application.
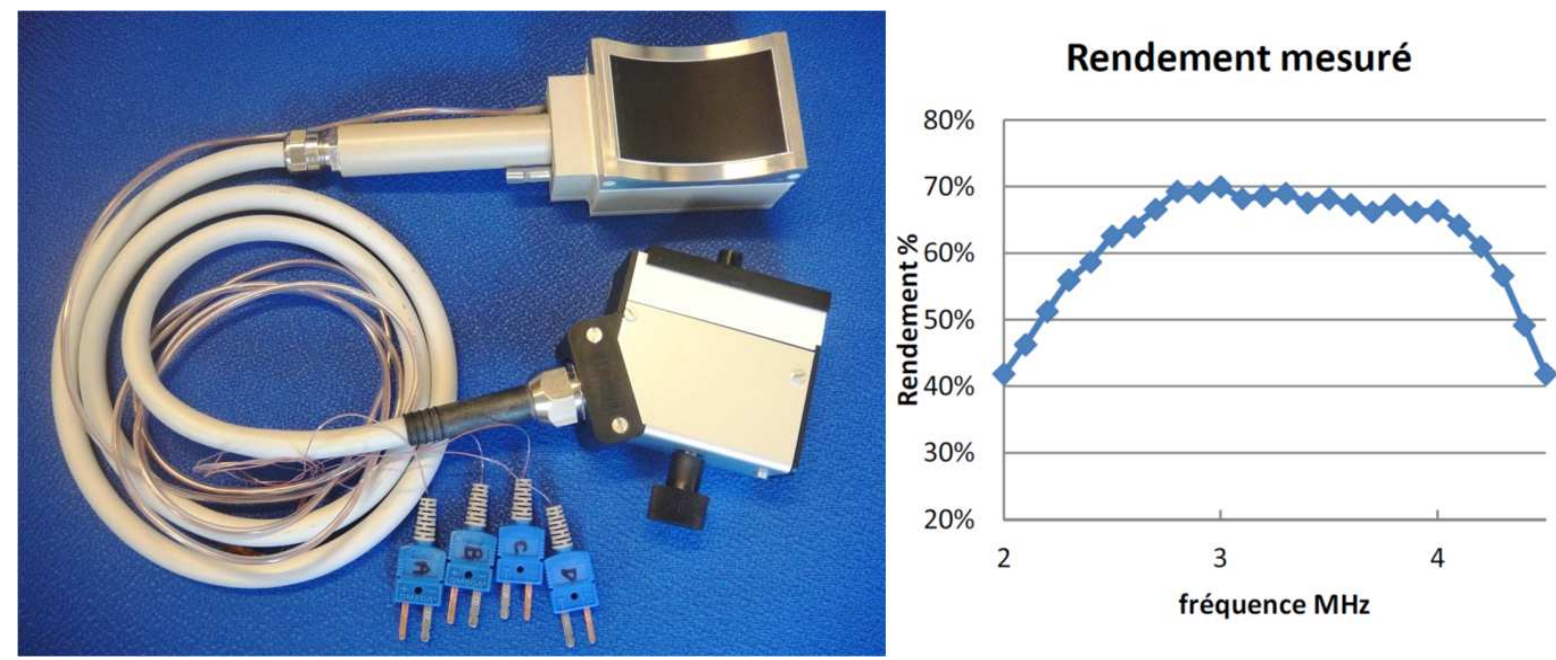

Figure 12: Pictures of the prototype of therapy probe (Left) and Therapy transducer power transmit efficiency for different frequencies (right).

\subsection{Segmentation and registration for intervention pre-planning}

A focal therapy for localized prostate cancer can be considered for a selected class patients $[8,9]$. One of the crucial issues is the precise localization of the tumor before the therapy planning and its precise position retrieval during the therapy. In a preoperative stage, among the various imaging modalities used for the exploration of the prostate tumors, only MRI can visualize the anatomy with sufficient contrast and resolution to discriminate the tumor within the prostate. However the delineation of the prostate on MRI, and even more the delineation of the tumor itself, is still an open problem (e.g. [23] for the prostate segmentation). In the per-operative stage, the imaging modality used to define and guide the HIFU therapy is $3 \mathrm{D}$ (or 2D in the case of a dual-mode probe) ultrasound imaging. In this imaging modality, the tumor itself cannot be discriminated within the prostate. Actually, only the transfer of the information extracted during the preoperative planning on the preoperative ultrasound image should allow retrieving the tumor location during the therapy. This transfer requires a phase of registration or fusion between the 3D MRI volume and the ultrasound 
images. Beside other considerations, several registration strategies can be considered according to the geometrical dimension (point, line, surface or volume) of the common information [21,24]. In the context of the MULTIP project two strategies are explored: volume to volume and surface to surface registration.

\subsubsection{Volume to volume registration}

By volume to volume we mean techniques that use the entire volume information to perform the registration. This class of techniques is also called intensity based registration. The main principle of these techniques is the following: 1) a similarity measure quantifies the degree of similarity between the intensity patterns in the two volumes, 2) geometrical transformations are performed on one volume in order to align it with the reference image, 3) the geometrical transformation which provide the highest similarity measure between the 2 volumes is searched by an optimization process. This class of methods is known to be relatively robust but cannot be directly used on US images because their characteristic feature is speckle and the intensity distribution of the speckle is not directly related to the several tissues. As an exploratory work in the MULTIP project, we proposed to use a new similarity measure no more related to the intensities but more related to the spatial organization of the intensities (the texture of the intensities). Texture estimation tools had some success in ultrasound image analysis. But, in our case, the circular US probe provides an irregular spatial speckle organization in orientation and scale over the image. In our study we proposed to use a texture analysis tool based on orthogonal moment invariants with respect to scale and rotation. The first results showed that orthogonal moment invariants where able to characterize not only the several region on US images but also the boundary between two regions (see Figure 13). But orthogonal moment invariants failed on characterizing the prostate in T2 MRI because of high slice thickness and moreover of the non-homogeneous information provided by the several prostate zones. In conclusion, a similarity measure only based on orthogonal moment invariants could not be implemented. So either a mix of orthogonal moment invariants and gray level should be used or the fall-back solution (surface to surface registration) should be investigated.
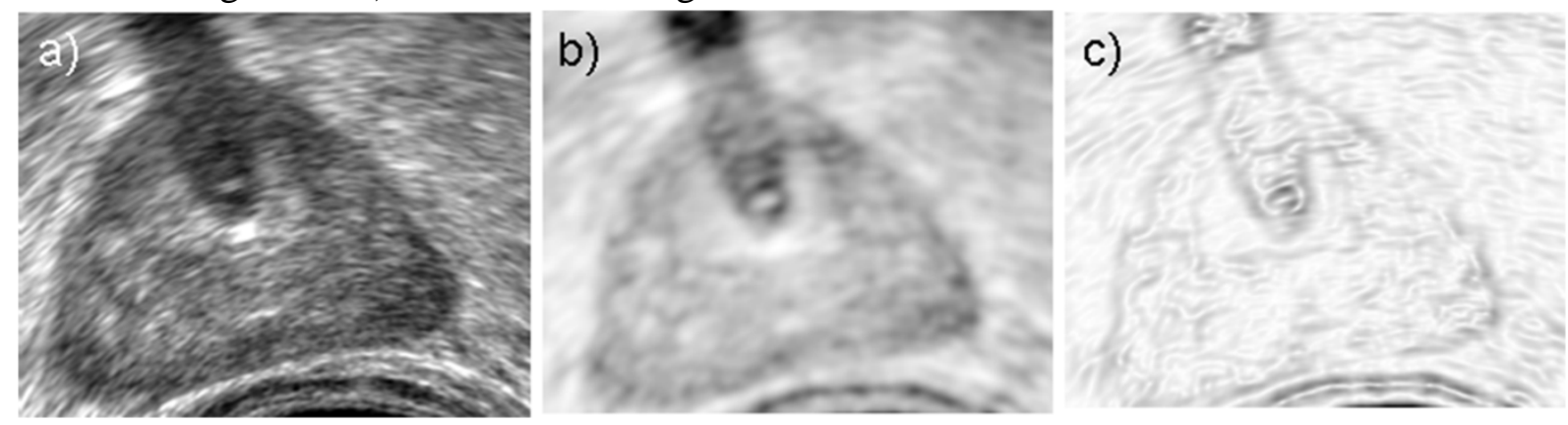

Figure 13: a) Original prostate image b) orthogonal moment invariant feature characterizing the regions c) orthogonal moment invariant feature characterizing the contours.

\subsubsection{Surface to surface registration}

Most of the work on MRI to ultrasound prostate image registration has been performed in this framework (e.g. the pioneer work of [25]). This framework is based on the delineation of the prostate external surface on both imaging modalities followed by an elastic registration 
on both surfaces. The accuracy of the registration is highly related to the accuracy of the prostate surface extraction. In a first step, we explored the prostate surface extraction on the 3D ultrasound volume provided by the Ablaterm ${ }^{\circledR}$ device. After a bibliographical research we decided to use a semi-automatic method in which the user defines 6 initial points (the prostate apex and base and 4 points in the mid axial prostate slice). These points allow defining an initial surface mesh. This surface is then refined on the US volume using the Discrete Dynamic Contour (DDC) or the Optimal Surface Detection (OSD) methods [26]. Both methods have some merits and have shown on the overall a quite good performance.

They always fall within the intra- and inter-observer variability interval. However, the OSD-based approach (Figure 14-a) provides slightly better results in terms of accuracy and requires less computation resources. In a second step we adapted the OSD approach to the T2 MRI prostate surface extraction. T2 MRI presents new segmentation difficulties in the sense that the prostate is not homogeneous (several prostate zones), its surface presents little information (hyposignal of the capsule) with gray level values close to these of the neighboring organs surface (bladder and rectum). We are working on a multi objects OSD segmentation scheme. Preliminary results on joint bladder and prostate segmentation can be seen on Figure 14-b.
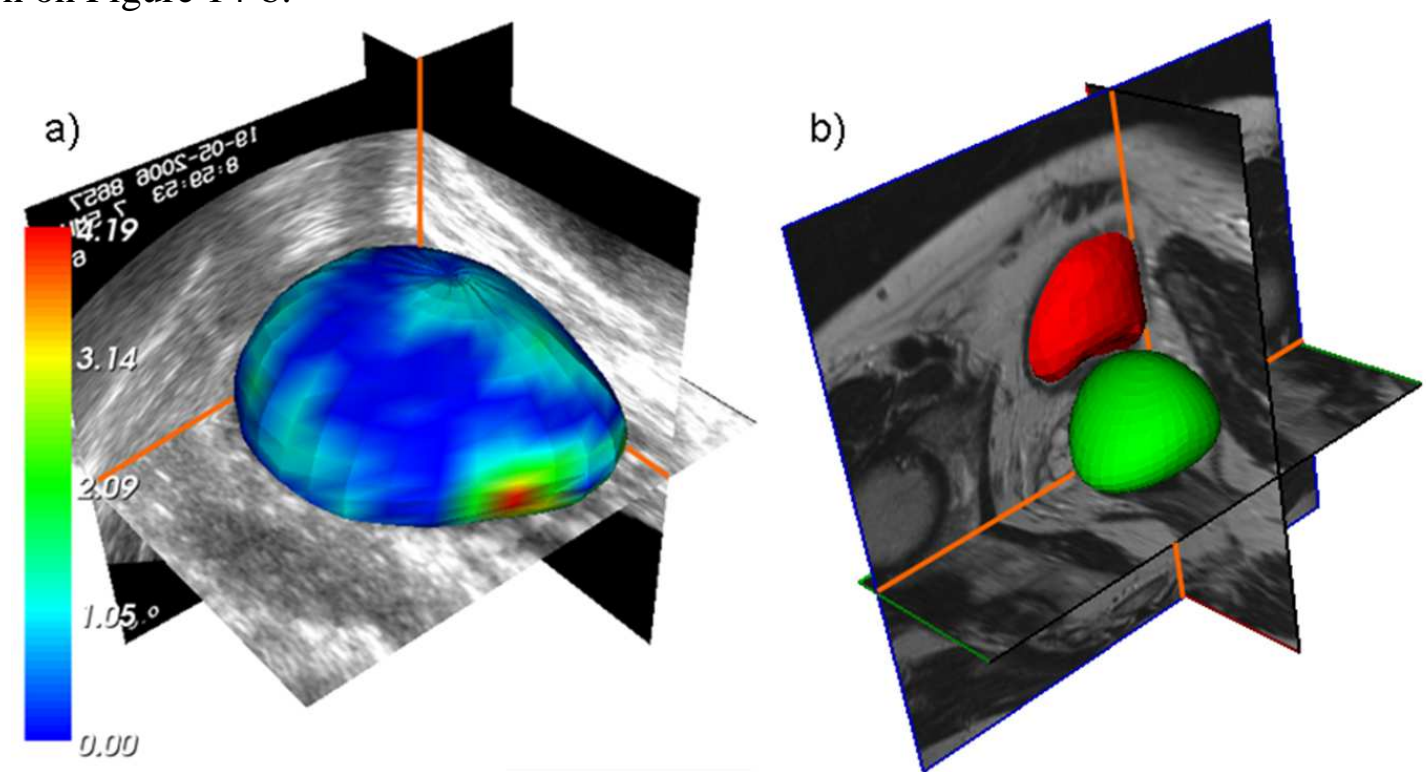

Figure 14: a) Prostate surface mesh extracted on a 3D US volume using Optimal Surface Detection. The color indicates the error between the estimated mesh and an expert contours extracted surface. b) Prostate (green) and bladder (red) surface meshes extracted on a T2 MRI volume using multi-objects Optimal Surface Detection.

\section{Discussion and conclusion}

The development of endocavitary dual-mode probes is essential for the accurate treatment of many deep seated cancers which require a high imaging resolution and the capacity to selectively treat focal areas in the region of interest. However the development of full 3D HIFU beam steering probes is extremely complex and the current technology does not allows cost effective manufacturing of such phased array therapy probes, and of the corresponding multi-channels electronics for delayed power transmissions. The MULTIP project aimed at determining under which conditions dual-mode ultrasonic probes can be 
designed to fulfill the therapeutic requirements of cancer-foci treatment while corresponding to the current technology available, so as to design a system which can be viably implemented in a commercial device. In order to allow the system to take advantage of the cutting edge imaging modalities, and to allow an efficient surgery planning, the technical study has been accompanied by a volume processing study aiming at permitting the design of the ultrasonic imaging/therapy process based on high resolution-high quality MRI images. The study was initiated in simulations, in order to determine, given the constrains of the application, the key parameters which remained to be defined. Different combinations of parameters including number of elements, pitch, center frequency and shape, were explored. Results showed that it is necessary to have a dual-mode probe which allows performing the imaging at a high frequency for a high resolution, while permitting to perform the therapy at a lower frequency. Regarding imaging simulations, the minimization of the grating lobes showed that a pitch of $1.2 \lambda$ for imaging at $6 \mathrm{MHz}$ is acceptable, but that the focal number needs to be adapted in different regions of the image to maintain an acceptable resolution. This implies the capacity of the probe to perform imaging also on a wide bandwidth. Regarding the therapy simulations the question of the number of simultaneous foci was studied, given that multiple foci allow the reduction of the number of electrical channels. However it has been observed that doing so reduces the energy transmitted to a given focus too severely in terms of local temperature elevation, and lead to the conclusion that a single focus was more efficient in terms of energy deposit. In order to further optimize the energy transmission, another study was conducted to determine the ideal therapy transducer subdivision. Such sub division impacts the beam shape and the energy deposit, but allows to reduce the number of power channels (limited here to 400 maximum for manufacturing purposes) and to simplify the wiring of the resulting probe. Conclusion is that while the 400 hundred channels are required to optimize the beam shape and its deflection abilities, an irregular grid allows achieving superior targeting resolution.

Based on these simulation results, prototypes have been manufactured and tested for imaging and therapy separately. Tests of the dual-mode section of the probe, showed that the bandwidth achieved is wide enough to cover the frequency domain established in simulation, and the transduction efficiency in therapy mode (48\%, then $70 \%)$ show that the dual-mode section reaches the efficiencies required for power transmission. Imaging tests on an Ultrasonix RP500 scanner showed that the images performed are of better quality than the one obtained using the previous probe design in similar imaging conditions. These results confirm once more the choices made in the simulation study, and the capacity of the resulting probe to perform high resolution imaging while allowing to transmit power at a lower frequency.

The study of the therapy probe prototype, which surrounds the dual-mode section, showed that the efficiency achieved is comparable to the one obtained in the previous but less complex models developed. The ratio of $70 \%$ reached at $3 \mathrm{MHz}$ demonstrates the high transduction capacity of the developed probe, which suggests that similar therapy efficiency should be achieved while allowing to take advantage of in-plane beam steering capacities. The following work planned before the end of this project include complementary characterizations of the second dual mode prototype (imaging $\&$ therapy capability) and of the therapy probe prototype (beam forming).

Finally, registration study of MRI volumes on ultrasound volumes, for the accurate planning of therapy session, has shown that it is more efficient to search at registering the 
surfaces of the volumes once they have been segmented ion each modality, rather than trying to register the two data volumes directly. Indeed the particular texture of the ultrasound images render direct registration difficult, and better success have been achieved by registering the surface of the prostates once each has been extracted from its own modality. While the current implementation is still semi automatic, which is still a common approach in intervention planning, future work will attempt to automate the segmentation and registration process.

The combination of high resolution therapy planning with high resolution per-operatory imaging, real-time registration, and accurate beam-steered focal therapy will allow in the future a fast and precise surgery, able to treat the diseased areas while sparing the biological tissues which can be saved [27].

\section{Acknowledgements}

This work was supported by the French National Research Agency (ANR) through the TecSan program (project MULTIP ANR-09-TECS-011).

\section{Conflict of interest}

The authors have not declared any conflicts of interest. IMASONIC is a company specialized in the design and manufacturing of ultrasonic transducers. EDAP TMS France is a company specialized in therapeutic ultrasound.

\section{References}

[1] Vincenot J, Melodelima D, Chavrier F, Vignot A, Chapelon J-Y. Augmentation du volume traité par ultrasons focalisés de haute intensité pour le traitement des métastases hépatiques. IRBM, Volume 32, Issue 5, November 2011, Pages 274-278.

[2] Fehrenbach J, Masmoudi M, Melodelima D. Low dimensional optimization for in vivo real-time porcine liver motion estimation using ultrasound imaging. Ultrasonics, Volume 50, Issue 1, January 2010, Pages 44-51.

[3] Melodelima D, Chapelon J-Y, Theillère Y, Cathignol D. Combination of thermal and cavitation effects to generate deep lesions with an endocavitary applicator using a plane transducer: ex vivo studies. Ultrasound in Medicine \& Biology, Volume 30, Issue 1, January 2004, Pages 103-111.

[4] Lafon C, Somaglino L, Bouchoux G, Mari J-M, Chesnais S, Ngo J, Mestas J-L, Fossheim S, Nilssen E, Chapelon J-Y. Feasibility study of cavitation induced liposomal doxorubicin release in an AT2 Dunning rat tumor model. J Drug Target. 2012 Sep;20(8):691-702.

[5] Crouzet S, Poissonnier L, Murat F-J, Pasticier G, Rouvière O, Mège-Lechevallier F, Chapelon J-Y, Martin X, Gelet A. Traitement du cancer localisé de la prostate avec l'appareil Ablatherm Imagerie Intégrée ${ }^{\circledR}$ : résultats carcinologiques et fonctionnels. Progrès en Urologie, Volume 21, Issue 3, March 2011, Pages 191-197.

[6] Crouzet S, Rebillard X, Chevallier D, Rischmann P, Pasticier G, Garcia G, Rouviere O, Chapelon J-Y, Gelet A. Multicentric Oncologic Outcomes of High-Intensity Focused 
Ultrasound for Localized Prostate Cancer in 803 Patients. European Urology, Volume 58, Issue 4, October 2010, Pages 559-566.

[7] Murat F-J, Poissonnier L, Rabilloud M, Belot A, Bouvier R, Rouviere O, Chapelon J-Y, Gelet A. Mid-term Results Demonstrate Salvage High-Intensity Focused Ultrasound (HIFU) as an Effective and Acceptably Morbid Salvage Treatment Option for Locally Radiorecurrent Prostate Cancer. European Urology, Volume 55, Issue 3, March 2009, Pages 640-649.

[8] Eggener S.E, Scardino P.T, et al. Focal Therapy for Localized Prostate Cancer: A Critical Appraisal of Rationale and Modalities, The Journal of Urology, Volume 178, Issue 6, 2007, Pages 2260-2267.

[9] Lazzeri M, Guazzoni G. Focal therapy meets prostate cancer, The Lancet, Volume 376, Issue 9746, 2010, Pages 1036-1037.

[10] Crouzet S, Koenig P, Haber GP, Benchikh A, Haffner J, Zini L, et al. Étude des variations de l'incidence et de l'incidence par stade des cancers de prostate à partir de 5 centres. Prog Urol 2008;18:Abstract 102.

[11] Uddin Ahmed H, Hindley R.G, Dickinson L, Freeman A, Kirkham A.P, Sahu M, Scott R, Allen C, Van der Meulen J, Emberton M. Focal therapy for localised unifocal and multifocal prostate cancer: a prospective development study. The Lancet Oncology, Volume 13, Issue 6, June 2012, Pages 622-632.

[12] Rouvière $\mathrm{O}$, Gelet $\mathrm{A}$, Crouzet $\mathrm{S}$, Chapelon JY. Prostate focused ultrasound focal therapy - imaging for the future. Nature Reviews, December 2012, Vol. 9, Nº12.

[13] Al-Bataineh O.M, Mast T.D, Park E, Sparrow V.W, Keolian R. M, and Smith N.B. Utilization of the k-Space Method in the Design of a Ferroelectric Hyperthermia Phased Array. Ferroelectrics, vol. 331, n. 1, p. 103, 2006.

[14] Chapelon J-Y, Cathignol D, Cain C, Ebbini E, Kluiwstra J.U, Sapozhnikov O.A, Fleury G, Berriet R, Chupin L, and Guey J-L. New piezoelectric transducers for therapeutic ultrasound. Ultrasound Med Biol, vol. 26, no. 1, pp. 153-159, Jan. 2000.:

[15] Curiel L, Chavrier F, Souchon R, Birer A, Chapelon J.Y. 1.5-D high intensity focused ultrasound array for non-invasive prostate cancer surgery. IEEE Transactions on Ultrasonics, Ferroelectrics, and Frequency Control, vol. 49, n . 2, p. 231-242, Fév. 2002.

[16] Jensen J.A. Field: A Program for Simulating Ultrasound Systems. Proceedings of the 10th Nordic-Baltic Conference on Biomedical Imaging Published in Medical \& Biological

[17] Shung K.K. The Principle of Multidimensional Arrays. Eur J Echocardiography (2002) 3, 149-153.

[18] Mari J-M, BouMatar O, Blu T, Cachard C, Unser M, A bulk modulus dependent linear model for acoustical imaging, J. Acoust. Soc. Am. 125, 2413 (2009).

[19] Tang M-X, Mari J-M, Eckersley R.J, Wells P.N.T. Attenuation correction in ultrasound contrast imaging: elementary theory and preliminary experimental evaluation. Ultr. in Med. Biol. Volume 34, Issue 12, pp 1998, 2008.

[20] Dillenseger J, Esneault S. Fast FFT-based bioheat transfer equation computation. Computers in Biology and Medicine, vol. 40, nº. 2, p. 119-123, Fév. 2010.

[21] Pluim J.P.W. and Fitzpatrick J.M., Image registration. IEEE Trans Med Imaging, Volume. 22, Issue. 11, 2003, Pages. 1341-1343.

[22] Wall M. Galib. A C++ Library of Genetic Algorithm Components. 12-Déc-1999. [Online]. Available: http://lancet.mit.edu/ga/. [Accessed: 31-Jan-2011]. 
[23] Promise12, MICCAI Grand Challenge: Prostate MR Image Segmentation 2012, http://promise12.grand-challenge.org/

[24] Zitová Z. and Flusser J. Image registration methods: a survey. Image and Vision Computing, Volume. 21, 2003, Pages 977-1000.

[25] Daanen V, Gastaldo J, et al. MRI/TRUS data fusion for brachytherapy." International Journal of Medical Robotics, Volume 2, Issue 3, 2006, Pages 256-261.

[26] Garnier C, Bellanger J-J, et al. Prostate segmentation in HIFU therapy. IEEE Transactions on Medical Imaging, Volume 30, Issue 3, 2011, Pages 792-803.

[27] Pichardo S, Gelet A, Curiel L, Chesnais S, Chapelon J-Y, New integrated imaging high intensity focused ultrasound probe for transrectal prostate cancer treatment. Ultrasound in Med. \& Biol., Vol. 34, No. 7, pp. 1105-1116, 2008. 